\title{
Websites as Information Hubs: How Informational Channel Integration and Shopping Benefit Density Interact in Steering Customers to the Physical Store
}

\author{
KRISTINA KLEINLERCHER, OLIVER EMRICH, DENNIS HERHAUSEN, PETER C. VERHOEF, \\ AND THOMAS RUDOLPH
}

\begin{abstract}
Multichannel retailers aim to steer customers to physical stores in order to increase cross-selling, benefit from higher margins, and offer multisensory experiences. The question of how retailers can steer customers to strategically important channels remains. We propose that retailers may induce customers to switch to physical stores by communicating information about channel integration on their websites and that this explicit communication is influenced by the implicit communication of shopping benefits of which customers and retailers may not be aware. Using a multilevel and multisource approach with field data on 1,479 customers and 104 firms, we find that informational online-to-physical channel integration on a retailer's website influences customers' online-to-physical store switching and that the density of concurrently communicated shopping benefits moderates this effect. Our results extend the literature on channel choice and provide implications for retailers regarding how to design websites as information hubs to steer customers to physical stores.
\end{abstract}

1 esearch suggests that multichannel retailers should foster seamless channel behavior from the website to the physical store because customers' spending tends to increase if they use the physical channel (Ansari, Mela, and Neslin 2008). Macy's reports that on average, customers spend 20\%-25\% more money than they had planned in physical stores (Halzack 2015). When exposed to products in a physical store, customers form new purchase motivations or remember forgotten ones and may increase their unplanned spending (Hui et al. 2013). In addition to increased cross-selling opportunities (Neslin and Shankar 2009; Gallino and Moreno 2014), physical stores also substantially contribute to a retailer's profits by providing higher margins than other channels. JC Penney, for example, states that its in-store sales are the most profitable sales across channels, and Rigby (2014) estimates a margin advantage of $2 \%-8 \%$ for store-based compared to online retailers. Furthermore, enhanced customer experiences with the help of an inspiring store design (Robertson, Gatignon, and Cesareo 2018), increased trust through personal interaction (Benedicktus et al. 2010), and a higher convenience of shopping in-store (Pauwels and Neslin 2015) may help multichannel retailers to strengthen their brand image (Wang and Goldfarb 2017) and increase the costs of switching to competitors (Brynjolfsson, Hu, and Rahman 2013). Therefore, it is not surprising that pure online players, such as Amazon and Zalando, have opened up physical stores and that an increasing number of multichannel retailers aim to steer customers from their websites to their physical stores.

Despite the many advantages that a retailer's physical store offers, the online shop's ability to provide customers with a vast amount of information anytime and anywhere has turned retailer websites into a highly important information source within the customer journey (Flavián, Gurrea, and Orús 2016). A retailer's website may act as an information hub that attracts customers early in their search phase

Kristina Kleinlercher (corresponding author; kristina.kleinlercher@unisg.ch) is a doctoral candidate of marketing, University of St. Gallen, Dufourstr. 40a, 9000 St. Gallen, Switzerland. Oliver Emrich (oemrich@uni-mainz.de) is a professor of management and social media, University of Mainz, Jakob-WelderWeg 9, 55128 Mainz, Germany. Dennis Herhausen (dennis.herhausen@unisg.ch) is an assistant professor of marketing, University of St. Gallen, Dufourstr. 40a, 9000 St. Gallen, Switzerland. Peter C. Verhoef (p.c.verhoef@rug.nl) is a professor of marketing, University of Groningen, Nettelbosje 2, 9747 Groningen, Netherlands. Thomas Rudolph (thomas.rudolph@unisg.ch) is a professor of marketing and international retail management, University of St. Gallen, Dufourstr. 40a, 9000 St. Gallen, Switzerland. The authors thank the participants of the conference at the Jay H. Baker Retailing Center at the Wharton School, June 22-23, 2017, for their valuable feedback. The customer survey used for this study was commissioned by the Institute of Retail Management. Kristina Kleinlercher was responsible for the data collection, and Dennis Herhausen was responsible for the data analysis.

JACR, volume 3, number 3. Published online June 25, 2018. http://dx.doi.org/10.1086/698415

(C) 2018 the Association for Consumer Research. All rights reserved. 2378-1815/2018/0303-0060\$10.00 
and displays information that may guide consumers through their shopping process (e.g., Pauwels et al. 2011). Approximately $70 \%$ of customers worldwide tend to search online before purchasing in physical stores (PricewaterhouseCoopers 2015), which makes so-called webrooming the most prevalent form of research shopping (Flavián et al. 2016). To prevent losing customers to competitors online, retailers integrate their online and physical channels (e.g., Cao and Li 2015; Emrich, Paul, and Rudolph 2015; Herhausen et al. 2015). Informational online-to-physical channel integration (hereafter ICI), defined as providing access to and information about the physical store on the retailer's website (Bendoly et al. 2005), has been found to increase perceptions of website quality and enhance search and purchase intentions at a multichannel retailer (Herhausen et al. 2015). More generally, channel integration is central to establishing a competitive advantage over pure online retailers and has been shown to increase sales growth over time (Cao and Li 2015).

To achieve and maintain a competitive advantage, retailers attempt to steer consumers toward their own strategically important channels. This process has become increasingly challenging because digital technologies enable unrestricted access to information disseminated by other customers, manufacturers, and independent providers that may influence customers' decision processes (Lemon and Verhoef 2016). Exerting too much control over customers' channel choice may lead to detrimental effects, such as customers negative reaction or weaker purchase intentions (Herhausen, Schögel, and Schulten 2012; Trampe, Konus, and Verhoef 2014). As such, a debate has unfolded regarding whether and how retailers may steer today's empowered customers to strategically important channels (Lemon and Verhoef 2016).

To address this research gap, we propose that by integrating information between online and physical stores, a retailer's website may act as an information hub that steers customers to physical stores. To date, research on physical channel integration (providing integrated services, such as click\&collect) and informational channel integration (one channel providing information about another) is scarce (Bendoly et al. 2005; Gallino and Moreno 2014; Herhausen et al. 2015). Given that physical channel integration is very costly for multichannel retailers and may not be sufficient to differentiate among retailers in the long run (Ofek, Katona, and Sarvary 2011), additional research on informational channel integration may help retailers to successfully steer customers to their physical stores. Focusing on the informational aspect of channel integration, we investigate how customers' channel choice is influenced by explicit communication about the physical store's resources on its website (i.e., ICI). Furthermore, we suggest that customers who are exposed to this explicit communication on the retailer's website may become more receptive to the implicit communication of shopping benefits associated with either the physical or the online channel (Verhoef, Neslin, and Vroomen 2007). The distinction between explicit and implicit communication refers to the notion that knowledge attainment is explicit for declarative, instructive, and actively processed knowledge and implicit for knowledge that is inferred from the context, which is often referred to as reading between the lines of information and practices (Griffith, Sawyer, and Neale 2003). As such, the context of shopping benefits communicated in conjunction with ICI may induce a (implicit) learning process regarding the relative advantages of physical stores versus online stores. Specifically, the density of informational shopping benefits may qualify (i.e., moderate) the impact of ICI on online-to-physical store switching (hereafter OSS) such that it becomes either strengthened or weakened. Previous studies have found that subtle website cues, such as symbols in the website's background (Mandel and Johnson 2002) or similarities between the web design and the physical store (Emrich and Verhoef 2015), influence customers' online purchase decisions. As these effects are very subtle, retailers may not necessarily be aware that these cues influence the effectiveness of ICI, thereby emphasizing the managerial importance of our research. We address two research questions for multichannel retailers:

1. What is the effect of explicit informational onlineto-physical channel integration (ICI) on customers' online-to-physical store switching (OSS)?

2. How does the implicit website information on shopping benefits moderate the effect of ICI on OSS? Specifically, when does implicit website communication about shopping benefits strengthen or weaken the effect of explicit ICI on OSS?

Our study investigates the role of the website as an information hub in a field setting using behavioral customer and objective firm data across major retail categories in Germany, Austria, and Switzerland. Extending previous studies on drivers of webrooming (searching online and purchasing in the physical store; e.g., Flavián et al. 2016; Gensler, Neslin, and Verhoef 2017), our study explores whether and how a retailer's website, serving as an information hub, can steer customers to its physical stores. Appendix A (apps. A-F are avail- 
able online) summarizes relevant studies that investigate interdependencies and synergies between channels. Existing online-to-physical channel integration studies have focused predominantly on assortment or price integration (e.g., Avery et al. 2012) but do not analyze how websites, as information hubs, may direct customers to channels merely with the help of ICI and its interplay with other website information. We provide a readily observable measurement scale for companies to assess their degree of ICI and uncover new managerial knowledge about the moderating effects of the website context.

\section{CONCEPTUAL DEVELOPMENT}

To explore the role of websites as information hubs, we consider retailers' explicit and implicit website communication and their joint effect on the likelihood of customers' onlineto-physical store switching as the dependent variable.

Regarding a retailer's explicit communication, we use the degree of informational online-to-physical channel integration as the independent variable. The degree of ICI varies depending on how much information about the physical store is accessible through the website. Providing knowledge about the physical store should help a retailer to complement the online channel with specific capabilities of the physical chan- nel (e.g., Herhausen et al. 2015). Examples include website information about physical store locations, in-store promotions, and in-store product availabilities.

A retailer's implicit communication of different shopping benefits on its website may further qualify the effect of ICI on OSS as a moderator. We define the density of informational shopping benefits as the frequency of a specific shopping benefit in relation to other shopping benefits in the website information surrounding channel integration. Subtle information cues that are communicated in the immediate surroundings of ICI may direct customers' attention toward specific aspects of the purchasing process that are associated with the physical channel and thus support the notion of OSS (e.g., Balasubramanian, Raghunathan, and Mahajan 2005). In line with this observation, Verhoef et al. (2007) state that retailers can strategically use comparative channel benefits to influence consumers' channel attitudes.

As summarized in our conceptual model (see fig. 1), we first propose an effect of retailers' explicit communication of ICI that makes consumers deliberatively assess resources concerning the physical channel and thus increases the likelihood of OSS. Second, we propose that this activating effect on customers' channel choice is further qualified by a retailer's implicit communication of shopping benefits, as-

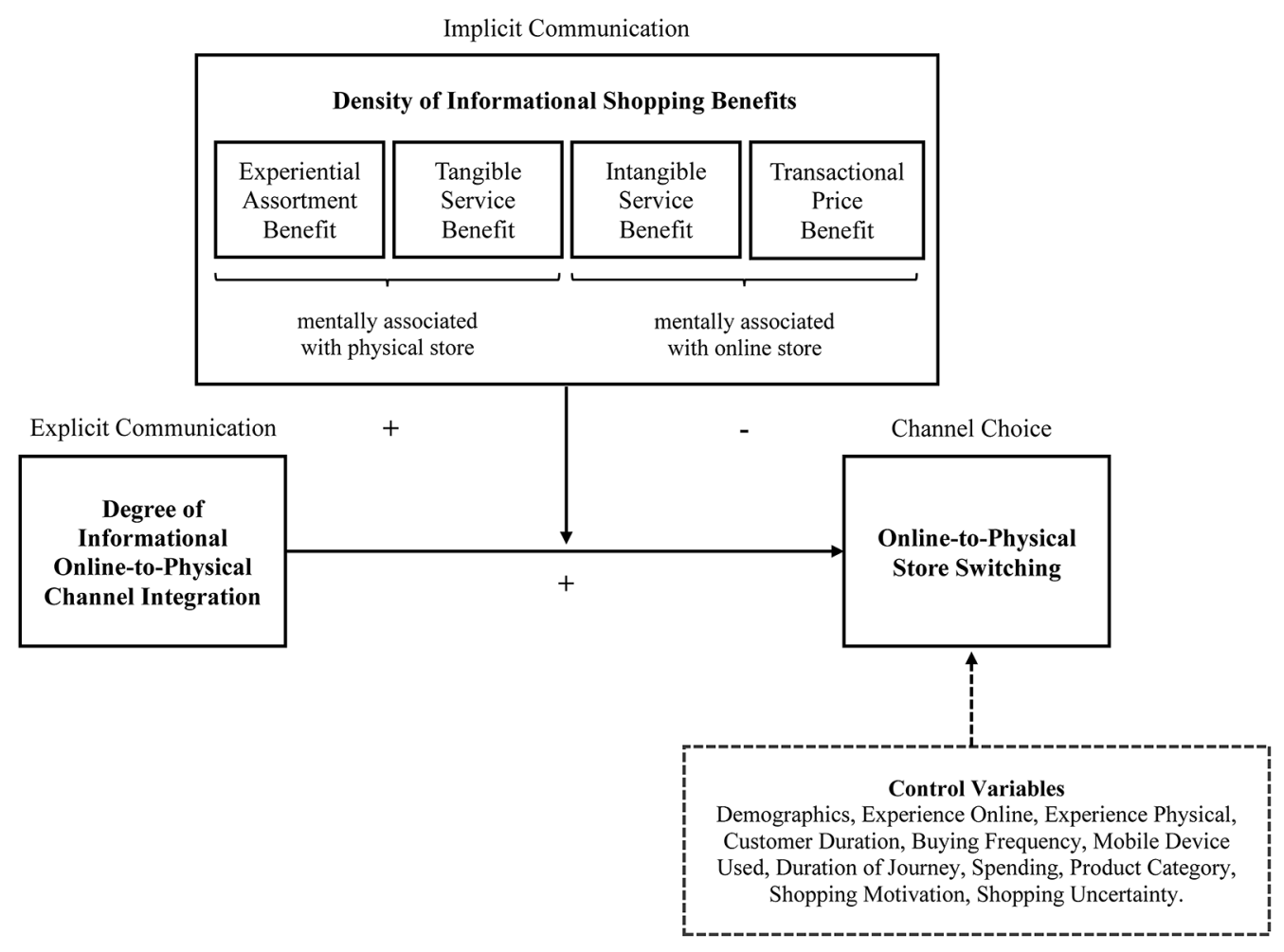

Figure 1. Customer steering with the website as an information hub. 
sociated with either the physical or the online channel, that either strengthens or weakens the effect of ICI on OSS. Although consumers may deliberately consider OSS based on ICI, a high density of shopping benefits in the immediate surroundings may automatically activate knowledge about stored channel advantages, in line with dual processing theory (e.g., Ophir, Nass, and Wagner 2009). Because this activation of implicit shopping benefits may be very subtle, we do not expect a direct effect (without ICI). However, the effects of ICI may still be highly sensitive to surrounding information on shopping benefits of which both retailers and customers may not be fully aware.

Based on previous research, we aggregate channel-related shopping benefits into four overall categories, encompassing experiential assortment benefits, tangible service benefits, intangible service benefits, and transactional price benefits (see app. B for a detailed description of the associations between shopping benefits and channels).

\section{Experiential Assortment Benefits}

According to Avery et al. (2012) and Verhoef et al. (2007), the physical channel is more strongly associated with experiential assortment benefits, such as opportunities to experience products, evaluate brands, and derive multisensory utilities. Although the online channel may contain more products at comparably low costs (also called a long tail), experiential benefits related to the assortment prevail for the physical channel because, in the store, customers have more opportunities to explore brands and products. From the customer's perspective, physical channels can better represent assortments (e.g., Verhoef et al. 2007), and many retailers try to offer their most important assortments in both channels, which largely offsets differences in the product range (Avery et al. 2012).

\section{Tangible Service Benefits}

Tangible service benefits encompass all aspects of a curated and immediate shopping experience at a retailer where customers value personal interaction with sales personnel and instant gratification for their efforts (Alba et al. 1997). A physical store provides a curated shopping experience through the opportunity to obtain face-to-face sales advice, to establish a relationship with the retailer, to negotiate prices, and to receive after-sales services (Avery et al. 2012). In addition, immediate benefits — such as instantly obtaining the physical product and avoiding delivery-may be experienced more strongly in a physical store than in an online store (Wang, Krishnamurthi, and Malthouse 2018).

\section{Intangible Service Benefits}

Intangible service benefits summarize fluid and streamlined benefits that the online channel can better provide, given its flexible interfaces and optimized transaction procedures (Alba et al. 1997). The online channel provides fluid benefits via greater information accessibility, lower search costs, more flexible opportunities to compare products, and the option to browse and purchase products from any place anytime, anywhere (Verhoef et al. 2007). Streamlined benefits arise from the efficiency, ease, and speed of making a purchase online and from the online channel's ability to recognize a consumer (e.g., via login or cookies) and provide personal settings based on previous transaction histories that facilitate the purchasing process (Avery et al. 2012).

\section{Transactional Price Benefits}

Whereas previous studies have indicated that a retailer's physical store may be in a better position to minimize monetary transaction costs (e.g., shipping charges) for the consumer (Avery et al. 2012), empirical results have shown that retailers more intensely compete on price online, that price levels are expected to be lower online, and that retailers use attractive price promotions more extensively online than in-store (Verhoef et al. 2007; Wolk and Ebling 2010).

\section{Other Potential Benefits}

Previous research has found channel-related differences in privacy benefits (e.g., Verhoef et al. 2007), which online stores frequently aim to provide. Those benefits are often communicated in conjunction with the online channel but cannot constitute a real advantage over physical stores, where high privacy levels are provided without any managerial intervention. Since we focus only on retail mix instruments, which are crucial to all multichannel retailers and must be dealt with on a regular basis (Zhang et al. 2010), we also do not consider social or fun-related shopping benefits. ${ }^{1}$

\section{HYPOTHESES}

\section{Explicit Multichannel Communication: The Effect of ICI on OSS}

Previous research has supported the notion that firms benefit from channel integration. Cao and Li (2015) find that the integration of online and physical channels positively influences a firm's sales growth, and Emrich et al. (2015) identify several channel integration strategies that increase

1. Including social- and fun-related shopping benefits as controls in the model leads to similar results. 
customers' patronage intentions. Verhoef et al. (2007) state that the level of cross-channel synergy between the retailer's website and the physical store positively influences channel switching, and Herhausen et al. (2015) find that online-to-physical channel integration does not cannibalize sales in the physical store but rather increases purchase intentions in the physical store. However, providing information about the physical store online may also negatively affect customers' OSS. Offering too many product alternatives on a retailer's website may result in confusion and dissatisfaction and deter customers from making a purchase decision (Lee and Lee 2004). Apart from consumer confusion, ICI may also increase the cognitive complexity of a retailer's website and thus interrupt flow in online environments (Hoffmann and Novak 2009). Despite potential detrimental effects of channel integration on channel switching, we argue that providing information about the physical store increases the desire of today's empowered customers to visit the physical store and engage in a seamless multichannel experience without restricting their autonomy.

H1: The degree of ICI on a retailer's website is positively associated with customers' likelihood of OSS.

\section{Implicit Multichannel Communication: The Moderating Effect of Shopping Benefit Density}

Channel choice depends on the benefits that customers wish to obtain from the purchase (Balasubramanian et al 2005). Because customers prefer a channel based on the specific benefits that they anticipate obtaining by using this channel, their behavior may be influenced by subtle information cues that activate those specific benefit mind-sets (Fiske and Taylor 2013). The more a specific shopping benefit is highlighted in relation to other shopping goals, the stronger the activation of the corresponding mind-set for obtaining this benefit will be. Therefore, we will regard the communicated shopping benefit density surrounding the explicit communication about ICI as a moderating influence on the impact of ICI on OSS. ${ }^{2}$ Whereas explicit communication about channel integration is intended to prompt channel switching and therefore directly activates behavioral intentions (Bagozzi

2. We decided to use shopping benefit density instead of a binary conceptualization of shopping benefit occurrence (0/1) because the frequency of a shopping benefit cue in relation to other shopping benefit cues correlates with the intensity by which customers process this information and thus predicts the weight of this information for their channel decision. We thank the editor for this suggestion. and Dholakia 1999), this implicit communication is more likely to trigger cognitions about shopping benefits that are only loosely connected with channel associations and become activated only if channel integration renders store switching salient (Fiske and Taylor 2013). Therefore, we will hypothesize how explicit communication about ICI may be qualified (i.e., moderated) by implicit communication about different types of shopping benefits when steering customers to the physical channel.

Experiential Assortment Benefits. Compared to the online channel, the physical store provides more opportunities to experience products based on sensory impressions, which enable customers to better assess product utility, enhance their brand awareness, and increase their purchase confidence (Avery et al. 2012; Jahn et al. 2018). When customers process website information about the physical channel, cues about experiential assortment benefits may further strengthen their intention to use the physical channel because customers' mind-sets become more strongly directed toward evaluating brands. For example, in fashion retailing, where brand experiences play an important role, online customers face a barrier to experiencing the product and are less confident about product attributes (Peck and Childers 2003). If the information cues activate mental concepts of brand experiences, the advantages of using a physical store with regard to touching, browsing, and feeling the assortments may implicitly support OSS intentions evoked by ICI. Additional evidence for the moderating impact of experiential assortment benefits results from empirical findings that customers perceive a retailer's physical store as the best channel for testing and purchasing popular brands, new products, and high-quality items (Verhoef et al. 2007).

H2: A high density of website cues related to experiential assortment benefits strengthens the positive relationship between ICI and customers' likelihood of OSS

Tangible Service Benefits. The physical store offers multiple services during the purchasing process that help customers receive curated advice and personal service delivery and provide them immediate access to physical consumption (Seiders et al. 2007). All these service benefits immediately result in tangible outcomes, such as immediate consumption access and immediate completion of product returns, and involve tangible face-to-face interactions that enhance the purchasing process (Avery et al. 2012). Website 
cues that refer to tangible service benefits may activate expectations regarding those specific service aspects that the physical store can better provide and therefore implicitly strengthen the impact of ICI on OSS intentions. For example, if website cues elicit a desire for instant gratification, this impulse may place more weight on intentions to switch to the physical channel and thereby make informational channel integration more effective (Gao, Li, and Wyer 2016). Alternatively, consider a customer who struggles to make a decision and who is exposed to website cues about personal assistance. In such a situation, the impact of ICI on OSS will be additionally strengthened by the impulse for tangible interactions with a real service counterpart (Flavián et al. 2016).

H3: A high density of website cues related to tangible service benefits strengthens the positive relationship between ICI and customers' likelihood of OSS.

Intangible Service Benefits. Compared to physical stores, online channels provide many opportunities to make shopping more flexible and to save time and effort (Verhoef et al. 2007). These fluid and streamlined processes are specific characteristics of online stores that are continually improved based on new technologies and access to individual customer profiles (Avery et al. 2012). When customers are exposed to these intangible service benefits, ICI may become less effective in steering customers to the physical store because the advantages of online shopping come more readily to mind and prevent customers from OSS. For example, from information cues related to their personal profiles, customers may be reminded that they can save time online because personalized shopping offers are automatically provided and shipping and credit card details are already stored. If those intangible service benefits are activated in customers' minds, the provision of information about other channels may less strongly increase OSS intentions.

H4: A high density of website cues related to intangible service benefits weakens the positive relationship between ICI and customers' likelihood of OSS.

Transactional Price Benefits. Even though additional monetary costs such as shipping costs may occur, consumers perceive prices to be lower online, and easy price comparisons and higher price transparency online strengthen the mental association between the online channel and transactional price benefits (Verhoef et al. 2007; Wolk and Ebling 2010).
When searching for price deals, customers prefer the online channel to physical stores (Verhoef et al. 2007) and research has found that showing consumers only price-related cues encourages them to assume low prices even if concurrent information is available (Inman, McAlister, and Hoyer 1990). This finding suggests that if price cues are presented in the same context, ICI will become less effective in steering customers to physical stores. Empirical studies support this notion: if the online store highlights price information, its lock-in effect might be higher (Balasubramanian et al. 2005). Emrich and Verhoef (2015) find that information about price competitiveness weakens the effectiveness of design integration across channels (i.e., a homogenous design across online and physical channels). Therefore, cues about transactional price benefits may similarly weaken the effect of ICI on OSS.

H5: A high density of website cues related to transactional price benefits weakens the positive relationship between ICI and customers' likelihood of OSS.

\section{METHODOLOGY Data Collection}

We test our hypotheses using multilevel and multisource data consisting of survey data collected in Austria, Germany, and Switzerland in 2016. The quotas chosen for age and gender distributions correspond to the population of internet users in the three countries. Customers who could not recall a multichannel retailer for which they knew the online store and the physical store were filtered out at the beginning. The screening criteria, together with quota requirements and unfinished surveys, involved 3,575 cases for which we did not receive complete data. Our sample encompassed 3,105 multichannel customers. Participants were asked to reconstruct their last purchase at a multichannel retailer that sells its products both online and in physical stores. Participants indicated at which retailer they had made the purchase, what they had bought, how much time had passed since they bought the item(s), and which touchpoints they had visited during the purchasing process. Since our analysis requires that participants have processed the website information, we analyzed only participants who visited the retailer's website (1,912 participants), and due to the multilevel structure of our analysis, we considered only retailers that were mentioned by at least five customers. Our final sample consists of 1,479 customers from 104 multichannel retailers. We limited the time interval between the survey participation and the last purchase to a maximum of three months to 
avoid inaccurate statements concerning customers' usage of the channels. We assisted participants in the reconstruction of their last purchase by providing a list of touchpoints offered by the retailer, its competitors, and independent providers. In a two-step process, participants were first asked to select those touchpoints that they visited during their specific purchasing process. Retailer-owned touchpoints refer to the entity from which the purchase was made and included the retailer's online store, physical store, catalog, newsletter, online community, mobile application, call center, radio/ TV spots, and live chat on the company's website. Competitorowned touchpoints included the physical store, online store, catalog, and newsletter of each respective competitor. Independent touchpoints encompassed search engines, manufacturer websites, social media, video portals, image portals, newspapers and printed media, communication with peers and friends, price comparison portals, product rating portals, and blogs and forums. After having indicated all the visited touchpoints for their last purchase, participants were again confronted with the touchpoints they had selected and had to indicate the order in which they had visited them with the help of a drag-and-drop function (see app. C).

We collected website data via manual coding. Within three months after the customer survey, a research assistant manually searched the websites of 104 retailers for ICI cues and for information on shopping benefits. To reduce coding error, we prepared a coding protocol, which specified the information to be extracted from each website. To ensure the reliability of the coding, a second research assistant independently coded all benefit dimensions on 30 randomly selected websites based on the coding protocol (interrater reliability $>$
.97). To rule out the possibility that website content had been changed between the customer's and the coders' website visits, we tested content changes on every fourth website with the internet archive WayBack Machine (https://archive.org /web/), finding that no changes were made to any website within six months.

\section{Measures}

The degree of ICI may range from the complete separation of channels to their complete integration (Neslin et al. 2006). In line with other studies (e.g., Cao and Li 2015), we aggregated information about ICI into a continuous measure. In the website coding (see table 1), we observed 10 different aspects of ICI that were discussed in previous research and confirmed in interviews with managers from two multichannel retailers. We created the measure for ICI by summing up the number of integration aspects on the relevant webpage for each retailer $(0=$ no ICI to $10=$ complete ICI $)$.

OSS is a dummy variable derived from the indicated touchpoint order in the survey ( $1=$ search on the retailer's website and purchase at the retailer's physical store; $0=$ search and purchase on the retailer's website; no catalog purchases at the focal multichannel retailer were indicated).

Data for the four shopping benefit densities were collected with the manual website coding, which observed how strongly the information surrounding ICI contained keywords that refer to each of the shopping benefits. Similar to text analysis applications, the density of each shopping benefit featured on each website was calculated by dividing the number of keywords found for a specific benefit (one dimension) by the number of all benefit-related words surrounding ICI found

Table 1. Degree of ICI (The Number of Integration Cues Was Summed Up for Each Retailer; $0=$ No ICI to $10=$ Complete ICI)

(1) Route planner to the physical store(s)

(2) Picture of the physical store(s)

(3) Video of the physical store(s)

(4) Availability of specific products in the physical store(s)

(5) Information about the physical store manager(s)

(6) Contact details for the physical store(s)

(7) Opening hours of the physical store(s)

(8) Information about products, which are only available in the physical store(s)

(9) Information about price promotions available in the physical store(s)

(10) Services offered in the physical store(s)
Bendoly et al. 2005

Bendoly et al. 2005; Darke et al. 2016

Bendoly et al. 2005; Darke et al. 2016

Cao and Li 2015; Herhausen et al. 2015

Cao and Li 2015; Darke et al. 2016

Bendoly et al. 2005

Bendoly et al. 2005

Bendoly et al. 2005; Cao and Li 2015

Cao and Li 2015

Cao and Li 2015; Herhausen et al. 2015 
Table 2. Share of Each Shopping Benefit's Association with the Online and Physical Store

Experiential Tangible Intangible

assortment service service Transactional benefit benefit benefit price benefit

\begin{tabular}{ccccc}
\hline $\begin{array}{c}\text { Physical store } \\
\text { association }\end{array}$ & 19.3 & 55.5 & 1.3 & 8.8 \\
$\begin{array}{c}\text { Online store } \\
\text { association }\end{array}$ & 4.1 & 6.5 & 52.0 & 26.4 \\
$\begin{array}{c}\text { Total channel } \\
\text { associations }\end{array}$ & 23.5 & 61.9 & 53.3 & 35.2 \\
\hline
\end{tabular}

on the retailer website's subpage. ${ }^{3}$ Appendix D provides a list of all the keywords used to characterize a specific benefit on the retailers' websites.

\section{Validation Check of the Association between Shopping Benefits and Channels}

We empirically tested the assumptions in the literature about the associations between specific shopping benefits and either the physical channel or the online channel. Specifically, for all shopping benefit keywords on the 104 retailer websites, we coded whether the keyword is mentioned in conjunction with the physical channel (physical store association), with the online channel (online store association), or with no specific channel. All associations between shopping benefits and channels are in the proposed conceptualized direction (see table 2). That is, experiential benefits and tangible service benefits were more often mentioned together with the physical channel, whereas intangible service benefits and transactional price benefits were more often mentioned together with the online channel.

We included several control variables, which may influence the effect of channel integration. We controlled for the effect of the product category on channel choice (Cao and Li 2015), for several demographic and psychographic variables, since certain customer characteristics may account for OSS tendencies (Falk, Schepers, and Hammerschmidt 2007), and for potential country effects. The measurement

3. To further test for the robustness of coding the shopping benefit densities on the ICI subpage, we coded the benefit-related words on the full website for eight retailers following the same coding protocol. The shopping benefit densities on the subpage and on the full website are highly correlated $(r=.88)$, supporting the robustness of our coding. of all variables is detailed in appendix E, and descriptive statistics and correlations are presented in appendix F.

The correlation table reveals that ICI is highest for electronics and, surprisingly, lowest for apparel. The average spending of $€ 225$ indicates that electronic purchases are rather expensive, making delivery insecure and susceptible to theft. Thus, ICI may be more important for customers of this category. In the apparel category, an average spending of $€ 80$ indicates that these purchases are less expensive. Together with the common practice of free shipping and free returns in Germany, Austria, and Switzerland, this lower average purchase price may explain the low channel integration in this category. Additionally, OSS is also highest for electronics and lowest for apparel, indicating further differences across categories.

\section{Analytical Strategy}

Given that customers provide their binary channel choice (online vs. physical store for purchase) on multiple retailers and, thus, customers are nested in retailers, we conducted a multilevel logistic regression analysis, with the channel switching to the physical store as the dependent variable, the degree of ICI as the independent variable, the four densities of benefit dimensions on the websites as moderators, and our control variables. We used a Bernoulli distribution for OSS and full maximum likelihood via EM-Laplace 2 approximation. The mixed model is specified as follows:

$$
\begin{aligned}
\eta_{i j}= & \gamma_{00}+\gamma \mathrm{ICI}_{j}+\gamma \text { Shopping Benefit Densities }_{j} \\
& +\gamma \mathrm{ICI}_{j} \times \text { Shopping Benefit Densities }_{j} \\
& +\gamma \text { Controls }_{i j}+u_{0 j},
\end{aligned}
$$

where $i=$ level 1 (consisting of 1,479 customers), $j=$ level 2 (consisting of 104 multichannel retailers), Prob(Channel Switching $\left._{i j}=1 \mid \beta j\right)=\eta_{i j}, \log \left[\phi_{i j} /\left(1-\phi_{i j}\right)\right]=\eta i j$, and level 1 variance $=1 /[\phi i j(1-\phi i j)]$.

\section{RESULTS}

\section{Control Variables}

Table 3 summarizes the results of our multilevel logistic regression analysis. Some control variables have a significant effect on OSS (model 1 ). The positive effect of physical experience on OSS $(\beta=.51, p<.01)$ indicates that customers who are accustomed to making purchases in the physical store have a tendency to return to the channel with which they are most familiar. The effect of using a mobile device on OSS is negative $(\beta=-1.88, p<.01)$, which indicates that customers who access the retailer's online store 
Table 3. Results of the Multilevel Logit Regression Analysis Predicting OSS

\begin{tabular}{|c|c|c|c|c|c|c|}
\hline & \multicolumn{2}{|c|}{ Model 1: Controls } & \multicolumn{2}{|c|}{ Model 2: Main Effect } & \multicolumn{2}{|c|}{ Model 3: Interaction Effects } \\
\hline & $\beta$ & SE & $\beta$ & SE & $\mathrm{B}$ & SE \\
\hline Intercept & $-.73^{* *}$ & .36 & $-1.01^{* * *}$ & .32 & $-.90^{* * *}$ & .34 \\
\hline \multicolumn{7}{|l|}{ Level 1 controls: } \\
\hline Spending & $-.13^{*}$ & .07 & $-.13^{*}$ & .07 & $-.11^{*}$ & .07 \\
\hline Gender (female) & .08 & .14 & .12 & .15 & .10 & .15 \\
\hline Age & -.11 & .08 & -.12 & .08 & -.13 & .08 \\
\hline Device (mobile) & $-1.88^{* * *}$ & .24 & $-1.92^{* * *}$ & .25 & $-1.95^{* * *}$ & .25 \\
\hline Duration of journey & $.38^{* * *}$ & .05 & $.37^{* * *}$ & .05 & $.38^{* * *}$ & .05 \\
\hline Education & -.03 & .07 & -.02 & .07 & .00 & .07 \\
\hline Household Size & -.03 & .06 & -.03 & .06 & -.03 & .06 \\
\hline Income & -.09 & .07 & -.10 & .07 & -.11 & .07 \\
\hline Urbanization & $.29^{* *}$ & .12 & $.29^{* *}$ & .12 & $.29^{* *}$ & .12 \\
\hline Experience online & -.07 & .07 & -.06 & .07 & -.06 & .08 \\
\hline Experience physical & $.51^{* * *}$ & .07 & $.52^{* * *}$ & .07 & $.53^{* * *}$ & .07 \\
\hline Customer duration & .08 & .06 & .09 & .07 & .08 & .07 \\
\hline Buying frequency & -.06 & .08 & -.06 & .08 & -.05 & .07 \\
\hline Hedonic shopping motivation & $.20^{* * *}$ & .05 & $.21^{* * *}$ & .05 & $.22^{* * *}$ & .06 \\
\hline Shopping uncertainty & -.08 & .06 & -.08 & .06 & -.07 & .06 \\
\hline Category apparel & -.18 & .29 & .10 & .31 & .16 & .30 \\
\hline Category electronics & .33 & .27 & .36 & .27 & .24 & .27 \\
\hline Category entertainment & .38 & .41 & .36 & .41 & .26 & .40 \\
\hline Category grocery & -.05 & .40 & .20 & .39 & .29 & .37 \\
\hline Category cosmetics & -.42 & .39 & -.28 & .39 & -.49 & .39 \\
\hline \multicolumn{7}{|l|}{ Level 2 main effects: } \\
\hline Country dummy Switzerland & .10 & .29 & .19 & .30 & .36 & .28 \\
\hline Country dummy Austria & .42 & .29 & $.52^{* *}$ & .25 & $.66^{* * *}$ & .25 \\
\hline $\mathrm{ICI}(\mathrm{H} 1+)$ & & & $.42^{* * *}$ & .15 & $.32^{* *}$ & .14 \\
\hline Experiential assortment cues [EAS] & & & -.13 & .11 & -.11 & .10 \\
\hline Tangible service cues [TAS] & & & -.23 & .15 & -.10 & .11 \\
\hline Intangible service cues [ITS] & & & .05 & .13 & .06 & .11 \\
\hline Transactional price cues [PRI] & & & $-.31^{* * *}$ & .12 & $-.23^{* *}$ & .10 \\
\hline \multicolumn{7}{|l|}{ Level 2 interaction effects: } \\
\hline $\mathrm{ICI} \times \mathrm{EAS}(\mathrm{H} 2+)$ & & & & & $.32^{* * *}$ & .09 \\
\hline $\mathrm{ICI} \times \mathrm{TAS}(\mathrm{H} 3+)$ & & & & & $.52^{* * *}$ & .13 \\
\hline $\mathrm{ICI} \times \mathrm{ITS}(\mathrm{H} 4-)$ & & & & & .17 & .11 \\
\hline $\mathrm{ICI} \times \mathrm{PRI}(\mathrm{H} 5-)$ & & & & & .04 & .09 \\
\hline-2 log likelihood & 4,349.99 & & $4,329.27$ & & $4,311.99$ & \\
\hline Change in fit $(d f)$ & & & $20.72^{* * *}(5)$ & & $17.28^{* * *}(4)$ & \\
\hline$N_{\text {Retailers }}$ & 104 & & 104 & & 104 & \\
\hline$N_{\text {Customers }}$ & 1,479 & & 1,479 & & 1,479 & \\
\hline
\end{tabular}

Note.-We used robust clustered standard errors and standardized all continuous variables. Category "other" is used as the base category in all analyses. Variance inflation factors for all predictors are below the critical value of 3 . Two-tailed tests:

${ }^{*} p<.10$.

${ }^{* *} p<.05$.

${ }^{* * *} p<.01$. 
via a smartphone are less likely to purchase at the retailer's physical store. A possible explanation for this effect is that customers are most likely to use mobile devices in the early stages of their customer journey and rather finalize their purchase online (via the laptop or desktop) after having switched from the mobile device (De Haan et al. 2015). Furthermore, we find that, as the customer spends more time from search to purchase, the likelihood that he/she will visit the physical store after visiting the website increases $(\beta=.38, p<.01)$. This finding is plausible, as customers who spend more time on their purchase are typically more involved in the purchase and wish to visit more channels to examine the product. The effect of hedonic shopping motivation on OSS is also positive $(\beta=.20, p<.01)$, supporting our assumption that physical stores provide more opportunities to enhance shopping experiences.

\section{Hypotheses Testing}

Adding the main effects in model 2 significantly improved the model fit $(\Delta=20.72, d f=5, p<.01)$. In support of $\mathrm{H} 1$, the significant positive relationship of the degree of ICI with OSS $(\beta=.42, p<.01)$ indicates that ICI drives customers to the physical store. This finding identifies customer steering as a new positive effect of ICI for multichannel retailers in addition to higher trust, higher search and purchase intentions, and higher willingness to pay (e.g., Cao and Li 2015; Darke et al. 2016; Herhausen et al. 2015).

Adding the interaction effects in model 3 significantly improved the model fit $(\Delta=17.28, d f=4, p<.01)$. In support of H2, we find that a high density of experiential assortment benefits on the surrounding webpage increases the relationship between ICI and OSS $(\beta=.32, p<.01)$. Simple slopes indicate that the effect of ICI on OSS is significant only when the surrounding information has a high density of experiential assortment benefits $(\beta=.64, p<$ $.01)$, but not if this density is low $(\beta=.00$, NS). Panel A in figure 2 graphically displays this relationship. Furthermore, in support of H3, we find that a high density of tangible service benefits increases the relationship between ICI and OSS $(\beta=.52, p<.01)$. Simple slopes indicate that the effect of ICI on OSS is significant only when the surrounding information has a high density of tangible service benefits $(\beta=.84, p<.01)$, but not if the density is low $(\beta=-.20$, NS; fig. 2, panel B).

According to $\mathrm{H} 4$, we expected the density of intangible service benefits to weaken the positive relationship between ICI and OSS. However, the results show no significant interaction effect, thus not supporting $\mathrm{H} 4(\beta=.17$, NS). One
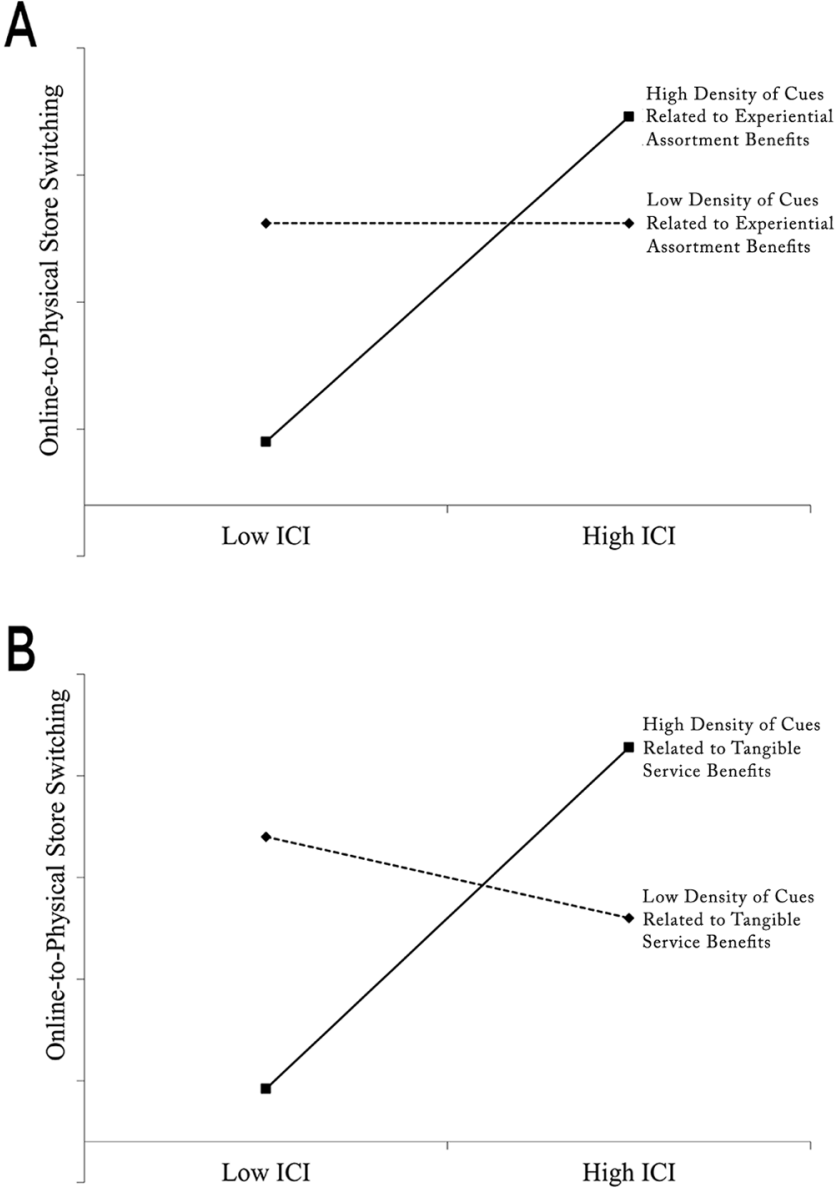

Figure 2. Amplifiers of informational online-to-physical channel integration. Panel A: assortment-related information cues. Panel B: information cues related to tangible services.

potential reason may be that the usefulness of the internet for searching and comparing products and prices has become so prevalent in customers' mind-sets that mentioning these benefits no longer moderates the influence of ICI on OSS. Rejecting H5, we find that a high density of transactional price benefits does not significantly decrease the relationship between ICI and OSS ( $\beta=.04, \mathrm{NS})$. Unexpectedly, we find a negative main effect of transactional price benefits on OSS, independent from the level of ICI. This main effect suggests that price-related information counteracts retailers' goals to steer customers from their websites to their physical stores, both with and without channel integration.

In sum, our results indicate that retailers can amplify the positive effect of ICI on OSS by highlighting experiential assortment benefits and tangible service benefits. However, retailers do not offset the effects of ICI on OSS by highlighting intangible service benefits. Interestingly, price-related information cues on a retailer's website are strong enough 
to prevent OSS without any additional channel references, creating a channel lock-in.

\section{Robustness Tests}

One might argue that customers may not have actively noticed the ICI cues on the website. Therefore, we analyzed whether customers who visited websites with a high degree of ICI noticed that the retailer offers information about the physical store on its website. In the survey, we assessed whether customers indicated that the retailer website they visited provided such integration (i.e., "The retailer offered knowledge about and access to the physical store on its website"; 7-point Likert scale from "do not agree" [1] to "fully agree" [7]). We aggregated the individual responses to the retailer level $\left(\operatorname{ICC}_{(2)}=.67\right)$ and found a strong correlation between the degree of ICI obtained from the website data and the perceived online-to-physical channel integration, as indicated by the customer data $(r=.51, p<.01)$. Thus, customers indeed noticed the ICI cues on the websites. Moreover, retailers may simultaneously provide different information cues about shopping benefits on their websites, and thus, these cues may have interrelated effects. Therefore, we explored all potential two-way interactions between the cues and all potential three-way interactions between ICI and the cues. None of these interactions was significantly related to OSS.

\section{DISCUSSION}

Our article extends previous findings on the beneficial effects of channel integration by providing an observable measurement scale to assess retailers' level of informational channel integration and showing that a higher degree of ICI on the website induces more OSS. Consumers' channel choice is influenced not only by retailers' explicit communication but also by very subtly communicated information cues that may occur without retailers' and consumers' awareness. The empirical design enabled us to detect those subtle influences, particularly if consumers are not aware of these effects, because we based our analysis not on self-reported perceptions of this subtle information but rather on observed information levels and densities on websites. Therefore, our findings also provide insights into the heated debate about whether retailers can still influence customer journeys in the multi-optional omnichannel world and how self-determined today's empowered consumers really are (e.g., Neslin and Shankar 2009).

Building on previous articles examining the influence of website cues on customer behavior (e.g., Emrich and Verhoef
2015) and based on a framework of associated channel benefits, our study analyzed the moderating impact of web cues. Our results show that information about experiential assortment benefits on the retailer's website induces a corresponding benefit-mind-set of customers that points them to the advantages of a physical channel with respect to brand awareness, brand experience, and purchase confidence and highlights the risks associated with purchasing the wrong product. In such a situation, information about the physical channel resources raises more attention and is more likely to lead to OSS. Similarly, we find that information about tangible service benefits strengthens the relationship between ICI and OSS because the potential disadvantages of online shopping (e.g., lower service levels in terms of support) may become more salient.

Transactional price benefits induce a strong focus on immediate rewards that can be gained by buying online. The negative direct effect found in our study suggests that customers consider price benefits online to be so strong (e.g., Gensler et al. 2017) that OSS is reduced. In that sense, price cues may be a way to create more online channel lock-in (Verhoef et al. 2007), thereby reducing webrooming. Our article did not provide evidence that stressing intangible service benefits, such as fluid and streamlined online processes, reduces the effect of ICI. Consumers tend to focus more strongly on the less subtle and more concrete retail mix elements, such as assortment and price, which may inform retailers' use of these retail mix instruments, depending on their goals.

From a managerial perspective, we highlight opportunities that arise from the design of websites as information hubs to create cross-channel synergies for firms and customers. If a retailer wants to steer customers to a physical store, websites containing ICI should include information related to experiential assortment and tangible services because such information reinforces the benefits of a physical store visit. Importantly, the benefits do not have to refer explicitly to a specific channel. Merely mentioning a benefit draws attention to a specific channel that is more strongly associated with this specific benefit in the consumer's mind. The high prevalence of shopping benefit information without any channel reference in our data (for assortment: $76.5 \%$; for price: $64.8 \%$ ) suggests that many retailers are not aware of these effects even though they have a strong impact on the effectiveness of channel integration. In our analysis, websites with ICI aspects contain a lot of transactional price information, which directly counteracts the desired OSS. Combining the explicit communication of chan- 
nel integration with the implicit communication of shopping benefits on their website, retailers might attract new floating customers or competitive research shoppers online, steer them to their physical stores, and increase their loyalty and crossbuying propensity as they enter the physical store (Verhoef and Donkers 2005). Importantly, these communication instruments can be implemented at very low costs and therefore should complement the costlier physical aspects of channel integration on which most retailers already focus.

One managerial limitation of our study is that it did not focus on switching to competitors, as we investigated channel-switching effects for the same retailer rather than competitive webrooming effects in which customers switch to competitors. However, previous research has conclusively shown that customers are more likely to stick to the multichannel retailer once the retailer integrates its channels (Herhausen et al. 2015). Therefore, at the very least, indirect effects of informational channel integration on long-term loyalty are likely to occur. Our study did not focus on the reverse switching behavior - from physical stores to online stores - because our goal was to investigate the role of the website as an information hub (used by the majority of consumers in their search phase). As an additional limitation, our shopping benefit density measure focused on the content of websites (keywords) but not on other factors that may influence the processing of benefits, such as color and the formatting of keywords or associated images (Mandel and Johnson 2002; Jiang and Fan 2018). Finally, our results do not provide insights into the OSS effect on firm performance. Future research may study the long-term financial effects associated with informational channel integration. However, since implementation costs are low, informational channel integration is most likely to benefit retailers.

\section{REFERENCES}

Alba, Joseph A., John Lynch, Barton Weitz, Chris Janiszewski, Richard Lutz, Alan Sawyer, and Stacy Wood (1997), "Interactive Home Shopping: Consumer, Retailer, and Manufacturer Incentives to Participate in Electronic Markets," Journal of Marketing, 61 (3), 38-53.

Ansari, Asim, Carl F. Mela, and Scott A. Neslin (2008), "Customer Channel Migration,” Journal of Marketing Research, 45 (1), 60-76.

Avery, Jill, Thomas J. Steenburgh, John Deighton, and Mary Caravelly (2012), "Adding Bricks to Clicks: Predicting the Patterns of CrossChannel Elasticities over Time," Journal of Marketing, 76 (3), 96-111.

Bagozzi, Richard P., and Utpal Dholakia (1999), "Goal Setting and Goal Striving in Consumer Behavior," Journal of Marketing, 63 (4), 19-32.

Balasubramanian, Sridhar, Rajagopal Raghunathan, and Vijay Mahajan (2005), "Consumers in a Multichannel Environment: Product Utility, Process Utility, and Channel Choice," Journal of Interactive Marketing, 19 (2), 12-30.
Bendoly, Elliot, James D. Blocher, Kurt M. Bretthauer, Shanker Krishnan, and M. A. Venkataramanan (2005), "Online/In-Store Integration and Customer Retention," Journal of Service Research, 7 (4), 313-27.

Benedicktus, Ray L., Michael K. Brady, Peter R. Darke, and Clay M. Voorhees (2010), "Conveying Trustworthiness to Online Consumers: Reactions to Consensus, Physical Store Presence, Brand Familiarity, and Generalized Suspicion," Journal of Retailing, 86 (4), 322-35.

Brynjolfsson, Erik, Yu Hu, and Mohammad Rahman (2013), "Battle of the Retail Channels: How Product Selection and Geography Drive CrossChannel Competition," Management Science, 55 (11), 1755-65.

Cao, Lanlan, and Li Li (2015), "The Impact of Cross-Channel Integration on Retailers' Sales Growth," Journal of Retailing, 91 (2), 198-216.

Darke, Peter R., Michael K. Brady, Ray L. Benedicktus, and Andrew E. Wilson (2016), "Feeling Close from Afar: The Role of Psychological Distance in Offsetting Distrust in Unfamiliar Online Retailers," Journal of Retailing, 92 (3), 287-99.

De Haan, Evert, P. K. Kannan, Peter C. Verhoef, and Thorsten Wiesel (2015), "The Role of Mobile Devices in the Online Customer Journey," Working Paper, Marketing Science Institute, Cambridge, MA.

Emrich, Oliver, Michael Paul, and Thomas Rudolph (2015), "Shopping Benefits of Multichannel Assortment Integration and the Moderating Role of Retailer Type," Journal of Retailing, 91 (2), 326-42.

Emrich, Oliver, and Peter C. Verhoef (2015), “The Impact of a Homogenous versus a Prototypical Web Design on Online Retail Patronage for Multichannel Providers," International Journal of Research in Marketing, 32 (4), 363-74.

Falk, Thomas, Jeroen Schepers, and Maik Hammerschmidt (2007), "Identifying Cross-Channel Dissynergies for Multichannel Service Providers," Journal of Service Research, 10 (2), 143-60.

Fan, Linying, and Yuwei Jiang (2018), "Don't Surprise Me: How Social Relationships Shape Consumers' Attitudes toward Probabilistic Selling," Journal of the Association for Consumer Research, 3 (3), in this issue.

Fiske, Susan T., and Shelley E. Taylor (2013), Social Cognition: From Brains to Culture, New York: McGraw-Hill.

Flavián, Carlos, Raquel Gurrea, and Carlos Orús (2016), “Choice Confidence in the Webrooming Purchase Process: The Impact of Online Positive Reviews on the Motivation to Touch," Journal of Consumer Behavior, 15 (5), 459-76.

Gallino, Santiago, and Antonio Moreno (2014), "Integration of Online and Offline Channels in Retail: The Impact of Sharing Reliable Inventory Availability Information,” Management Science, 60 (6), 1434-51.

Gao, Leilei, Yanjie Li, and Robert S. Wyer Jr. (2016), “Choosing between Two Evils: The Determinants of Preferences for Two Equally GoalInconsistent Options," Journal of Consumer Research, 42 (6), 1002-12.

Gensler, Sonja, Scott A. Neslin, and Peter C. Verhoef (2017), "The Showrooming Phenomenon: It's More than Just about Price," Journal of Interactive Marketing, 38 (2), 29-43.

Griffith, Terri L., John E. Sawyer, and Margaret A. Neale (2003), "Virtualness and Knowledge in Teams: Managing the Love Triangle of Organizations, Individuals, and Information Technology," MIS Quarterly, 27 (2), 265-87.

Halzack Sarah (2015), "From New Mobile Offerings to a Potential OffPrice Business, a Look at What's in Store for Macy's," Washington Post, January 30

Herhausen, Dennis, Jochen Binder, Marcus Schoegel, and Andreas Herrmann (2015), "Integrating Bricks with Clicks: Retailer-Level and Channel-Level Outcomes of Online-Offline Channel Integration," Journal of Retailing, 91 (2), 309-25. 
Herhausen, Dennis, Marcus Schögel, and Matthias Schulten (2012), "Steering Customers to the Online Channel: The Influence of Personal Relationships, Learning Investments, and Attitude toward the Firm," Journal of Retailing and Consumer Services, 19 (3), 368-79.

Hoffmann, Daniel L., and Thomas P. Novak (2009), "Flow Online: Lessons Learned and Future Prospects," Journal of Interactive Marketing, 23 (1), 23-34.

Hui, Sam K., Jeffrey Inman, Yanliu Huang, and Jacob Suher (2013), “The Effect of In-Store Travel Distance on Unplanned Spending: Applications to Mobile Promotion Strategies," Journal of Marketing, 77 (2), 1-16.

Inman, Jeffrey J., Leigh McAlister, and Wayne D. Hoyer (1990), "Promotional Signal: A Proxy for Price Cut," Journal of Consumer Research, 17 (1), 74-81.

Jahn, Steffen, Tim Nierobisch, Waldemar Toporowski, and Til Dannewald (2018), "Selling the Extraordinary in Experiential Retail Stores," Journal of the Association for Consumer Research, 3 (3), in this issue.

Lee, Byung-Kwan, and Wei-Na Lee (2004), "The Effect of Information Overload on Consumer Choice Quality in an Online Environment," Psychology and Marketing, 21 (3), 159-83.

Lemon, Katherine N., and Peter C. Verhoef (2016), "Understanding Customer Experiences throughout the Customer Journey," Journal of Marketing, 80 (6), 69-96.

Mandel, Naomi, and Eric J. Johnson (2002), "When Web Pages Influence Choice: Effects of Visual Primes on Experts and Novices," Journal of Consumer Research, 29 (2), 235-45.

Neslin, Scott A., Dhruv Grewal, Robert Leghorn, Venkatesh Shankar, Marije L. Teerling, Jaqueline S. Thomas, and Peter C. Verhoef (2006), "Challenges and Opportunities in Multichannel Customer Management," Journal of Service Research, 9 (2), 95-112.

Neslin, Scott A., and Venkatesh Shankar (2009), "Key Issues in Multichannel Customer Management: Current Knowledge and Future Directions," Journal of Interactive Marketing, 23 (1), 70-81.

Ofek, Elie, Zsolt Katona, and Miklos Sarvary (2011), “'Bricks and Clicks': The Impact of Product Returns on the Strategies of Multichannel Retailers," Marketing Science, 30 (1), 42-60.

Ophir, Eyal, Clifford Nass, and Anthony D. Wagner (2009), "Cognitive Control in Multimedia Multitaskers," Proceedings of the National Academy of Sciences, 106 (37), 583-87.

Pauwels, Koen, Peter S. H. Leeflang, Marije L. Teerling, and K. R. Eelko Huizingh (2011), "Does Online Information Drive Offline Revenues? Only for Specific Products and Consumer Segments!” Journal of Retailing, 87 (1), 1-17.
Pauwels, Koen, and Scott A. Neslin (2015), "Building with Bricks and Mortar: The Revenue Impact of Opening Physical Stores in a Multichannel Environment," Journal of Retailing, 91 (2), 182-97.

Peck, Joann, and Terry L. Childers (2003), "To Have and to Hold: The Influence of Haptic Information on Product Judgements," Journal of Marketing, 67 (2), 35-48.

PricewaterhouseCoopers (2015), “Total Retail 2015: Retailers and the Age of Disruption,” https://www.pwc.com/sg/en/publications/assets/to tal-retail-2015.pdf.

Rigby, Darrell K. (2014), “Online Shopping Isn't as Profitable as You Think," Harvard Business Review, August 21, https://hbr.org/2014 /08/online-shopping-isnt-as-profitable-as-you-think.

Robertson, Thomas, Hubert Gatignon, and Ludovica Cesareo (2018), "PopUps, Ephemerality, and Consumer Experience: The Centrality of Buzz," Journal of the Association for Consumer Research, 3 (3), in this issue.

Seiders, Kathleen, Glenn B. Voss, Andrea L. Godfrey, and Dhruv Greval (2007), "SERVCON: Development and Validation of a Multidimensional Service Convenience Scale," Journal of the Academy of Marketing Science, 35 (1), 144-56.

Trampe, D., Umut Konus, and Peter C. Verhoef (2014), "Customer Responses to Channel Migration Strategies toward the E-Channel," Journal of Interactive Marketing, 28 (4), 257-70.

Verhoef, Peter C., and Bas Donkers (2005), "The Effect of Acquisition Channels on Customer Loyalty and Cross-Buying," Journal of Interactive Marketing, 19 (2), 31-42.

Verhoef, Peter, C., Scott A. Neslin, and Björn Vroomen (2007), "Multichannel Customer Management: Understanding the Research-Shopper Phenomenon," International Journal of Research in Marketing, 24 (2), 129-48.

Wang, Kitty, and Avi Goldfarb (2017), "Can Offline Stores Drive Online Sales?" Journal of Marketing Research, 54 (5), 706-19.

Wang, Rebecca Jen-Hui, Lakshman Krishnamurthi, and Edward C. Malthouse (2018), "When Reward Convenience Meets a Mobile App: Increasing Customer Participation in a Coalition Loyalty Program," Journal of the Association for Consumer Research, 3 (3), in this issue.

Wolk, Agnieszka, and Christine Ebling (2010), "Multi-Channel Price Differentiation: An Empirical Investigation of Existence and Causes," International Journal of Research in Marketing, 27 (2), 142-50.

Zhang, Jie, Paul W. Farris, John W. Irvin, Tarun Kushwaha, Thomas J. Steenburgh, and Barton A. Weitz (2010), "Crafting Integrated Multichannel Retailing Strategies," Journal of Interactive Marketing, 24 (2), 168-80. 